\title{
Modification of gas-thermal coatings surface by continuous-generation laser radiation
}

\author{
Evgeniy A. Chaschin ${ }^{1}$, Konstantin I. Kurganov ${ }^{2}$, Andrey A. Mitrofanov ${ }^{1}$, \\ Andrey H. Kharakhashev ${ }^{3,}$, and Mikhail M. Klimov ${ }^{3}$ \\ ${ }^{1}$ Kovrov State Technological Academy, 601910 Kovrov, Russia \\ ${ }^{2}$ Ivanovo State Power University, 153000 Ivanovo, Russia \\ ${ }^{3}$ Don State Technical University, 344000 Rostov-on-Don, Russia
}

\begin{abstract}
The results of the researches which determine the dependence of gas-thermal coating porosity on the laser radiation parameters are given in the article. The coatings which are based on the metallic (PN-85-U-15) and non-metallic $\left(\mathrm{Al}_{2} \mathrm{O}_{3}\right)$ components were analyzed. The quantitative assessment of porosity modification were realized by means of the based on Visual Studio 2008 program. This image processing program allows to com-pare the microstructure of the occupied by pores and coating material areas pixel-by-pixel. It has been established that the action of laser radiation leads to reduction of average porosity of gas-thermal coating. This reduction is: 1. the porosity in the initial position for coating of a PN $85-\mathrm{U}-15$-based alloy is $17 \%$; after the laser treatment it's $5-8 \%$; $2 .-$ the porosity in the initial position for ceramic coating of $\mathrm{Al}_{2} \mathrm{O}_{3}$ is $24,5 \%$; after the laser treatment it's $15-18 \%$.
\end{abstract}

\section{Introduction}

It is known that one of the methods of obtaining protective coatings of increased strength is plasma application of these coatings $[1,2]$. The effective application of functional gasthermal coatings is determined not only by the properties of the sprayed material, which is quite obvious, but also by the characteristics of the coating. So, for example, the heatshielding ability and corrosion resistance of a coating is largely determined by its porosity. With increasing porosity, the heat-shielding characteristics of the coating are improved, in particular heat resistance, resistance to cracking under thermal cyclic loads. On the other hand, the developed external and internal porosity facilitates the possibility of penetration of atmospheric gases or hostile environments through the coating to the surface of the metal substrate, resulting in formation of oxide films at the boundary, a decrease in the adhesion strength, and peeling of the coating [3]. Reducing the porosity of surface coatings is possible by fusing of a certain volume of particles in the coating composition. In this case, the dispersed sprayed coatings should be fused, excluding volumetric heating up to the melting point of the coatings, since this can lead to peeling of the coatings due to both fusing of the substrate and a significant thermal deformation of the substrate. It is known

\footnotetext{
*Corresponding author: andronh@mail.ru
} 
that exposure to laser radiation provides high-temperature heating, characterized by a small heat-affected zone [4].

\section{Experimental results}

An experiment was carried out to spray two types of coatings on experimental samples of structural steel of mark 10 using the "Kiev-7" unit: ceramic based on $\mathrm{Al}_{2} \mathrm{O}_{3}$ and based on the alloy PN 85-U-15. The dispersity of the particles of the sprayed powder in both cases was 40-60 $\mu \mathrm{m}$. The thickness of the sprayed layers was approximately $300 \mu \mathrm{m}$. Laser processing of each type of coating was carried out using continuous radiation of $\mathrm{CO}_{2}$ laser and was accompanied by a fusion of the surface layer.

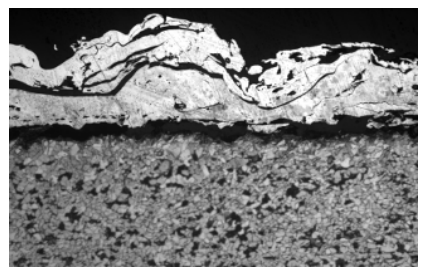

$a$

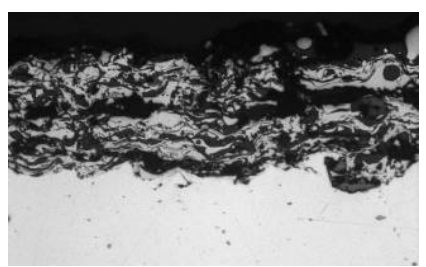

$d$

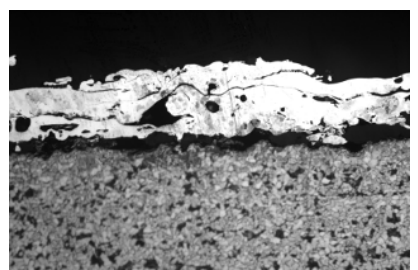

$\boldsymbol{b}$

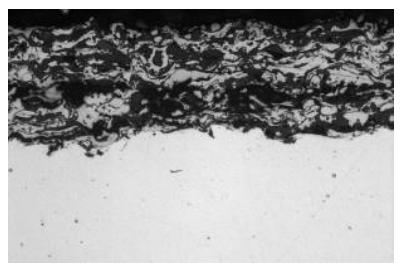

$e$

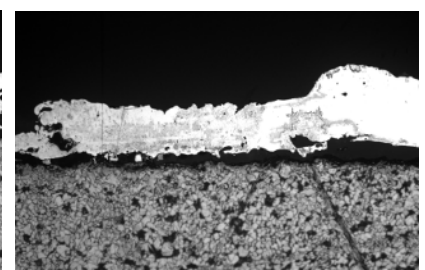

$\boldsymbol{c}$

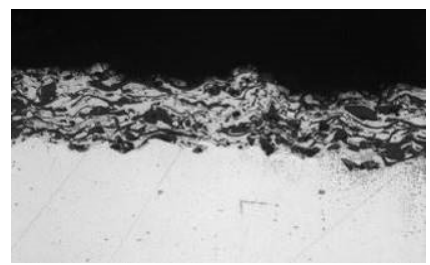

$f$

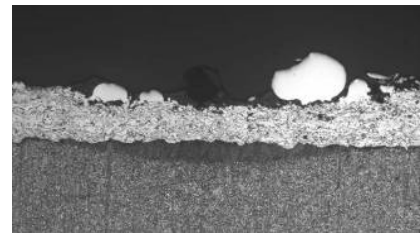

$g$

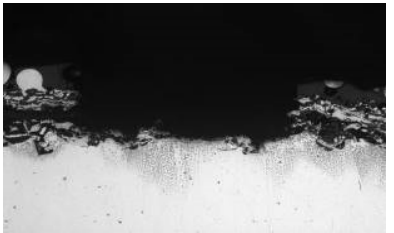

$\boldsymbol{h}$

Fig. 1. Microstructure of the plasma coating based on the alloy $85-\mathrm{YU}-15 \mathrm{PN}(a, b, c)$ and ceramic coating of $\mathrm{Al}_{2} \mathrm{O}_{3}(d, e, f, g, h)$ before and after treatment with $\mathrm{CO}_{2}$ laser radiation $(\times 100): a-$ initial state; $b$ - after exposure to radiation with a power density of $1.5 \times 106 \mathrm{~W} / \mathrm{cm}^{2} ; c-$ after exposure to radiation with a power density of $1.8 \times 106 \mathrm{~W} / \mathrm{cm}^{2} ; d$-initial state; $e$-after exposure to radiation with a power density of $1.6 \times 106 \mathrm{~W} / \mathrm{cm}^{2} ; f$-after exposure to radiation with a power density of $3.8 \times 106 \mathrm{~W} / \mathrm{cm}^{2} ; g$ - after exposure to radiation with a power density of $4 \times 106 \mathrm{~W} / \mathrm{cm}^{2}$ (partial evaporation of the coating; $h$-after exposure to radiation with a power density of $4.5 \times 106 \mathrm{~W} / \mathrm{cm}^{2}$ (total evaporation of the coating)

To investigate the structure, transverse metallographic microsection were made. It has been established that qualitative changes occur in the structure of the plasma coating based on the PN 85-U-15 alloy (Fig. 1, a-c). Apparently as the power density of laser radiation increases, the area occupied by dark zones, known as closed pores, decreases. Also there is a decrease in the relief of the surface layer of the coating in the laser exposure zone, which additionally indicates existence of fusing processes. 
Similar studies were carried out for the ceramic coating $\mathrm{Al}_{2} \mathrm{O}_{3}$. However, the intensity of the process of changing the porosity is much lower (Fig. 1, d-f). It can be substantially caused by great values of temperatures of melting and boiling of $\mathrm{Al}_{2} \mathrm{O}_{3}$ in comparison with material of PN 85-U-15 alloy. Further increase in density of power of laser radiation to $4-$ $4,5 \times 10 \mathrm{~W} / \mathrm{cm}$ during the processing of the covering of $\mathrm{Al}_{2} \mathrm{O}_{3}$ to partial (Fig. 1, g) or to full evaporation of the covering from a substrate surface (Fig. $1, \mathrm{~h}$ ).

The shape of the pores of the sprayed coating is complex and depends on both the shape and size of the particles, as well as the spraying conditions and subsequent processing.

Evaluating of porosity change was conducted using the image processing program developed in the Visual Studio 2008 environment, that is based on the known method [5] that uses the pixel-by-pixel comparison of the area of dark (pores) and light (coating material) zones in the image of the microstructure of the transverse sections of the experimental samples.

A qualitative distribution of the pore volume along the depth of the coating material is shown in Fig. 2 and 3. The distribution of porosity in the depth of the sprayed coating in the absence of laser exposure is uneven (curve 1), which is primarily caused by uneven heating of the sections during spraying and matches known dependences [6]. Thermal exposure to laser radiation causes decrease in porosity. At the same time, the intensity of the impact significantly affects the porosity on the surface of the material (curves 2 and 3 ) and minimum level of porosity is observed at temperatures close to boiling (curve 3 ).

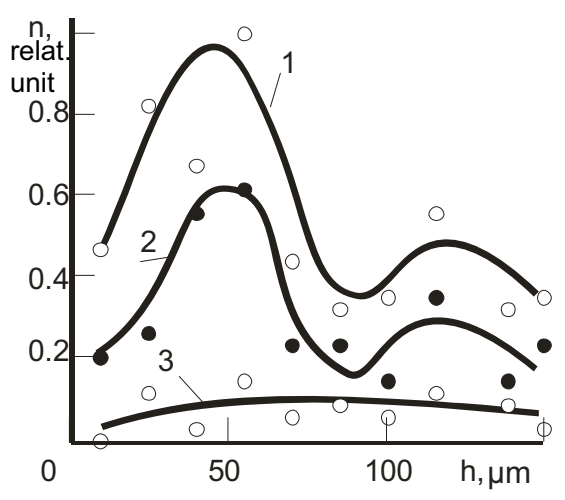

Fig. 2. Change in porosity in the depth of the coating based on the PN 85-U-15 alloy at different laser radiation power densities: 1 - initial state; 2 - after exposure to radiation with a power density of $1.5 \times 106 \mathrm{~W} / \mathrm{cm}^{2}$; 3 - after exposure to radiation with a power density of $1.8 \times 106 \mathrm{~W} / \mathrm{cm}^{2}$.

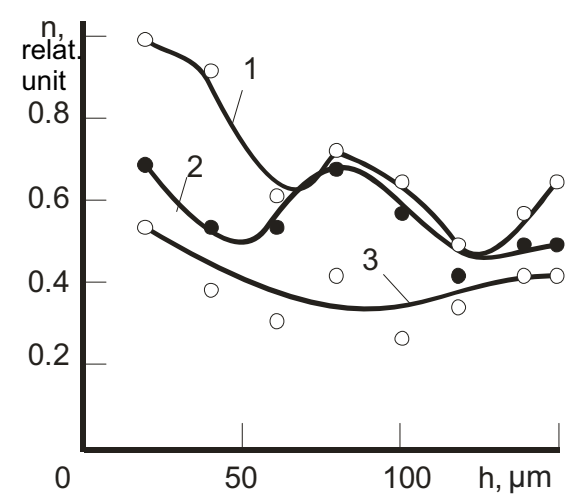

Fig. 3. Change in porosity in the depth of the coating based on the $\mathrm{A} 12 \mathrm{O} 3$ alloy at different laser radiation power densities: 1 - initial state; 2 - after exposure to radiation with a power density of $1.6 \times 106 \mathrm{~W} / \mathrm{cm}^{2} ; 3$ - after exposure to radiation with a power density of $3.8 \times 106 \mathrm{~W} / \mathrm{cm}^{2}$.

It can be seen that the greatest decrease in the porosity of all types of coating occurs in the upper layers, which are heated to higher temperatures in comparison with the underlying ones.

The quantitative results of the average porosity in the cross-section are shown in Table. 1. Fro the results obtained, it can be seen that exposure to laser radiation leads to a decrease in the average depth of the coating porosity. This process is most intensive in a coating based on the PN 85-U-15 alloy. In this case, the porosity decreases 2 - 3 times from $17 \%$ atits initial state to $5-8 \%$ after laser processing. For the ceramic coating of $\mathrm{Al}_{2} \mathrm{O}_{3}$, the effect of laser radiation is less affected by the change in porosity, the value of which decreases 1.3-1.6 times from $24 \%$ in the initial state to $15-18 \%$ after laser processing. Obviously, it is 
caused by the higher values of the melting and boiling points of the ceramic coating of $\mathrm{Al}_{2} \mathrm{O}_{3}$ as compared to the PN 85-U-15 alloy.

Table 1. Change in porosity of gas-thermal coatings as a result of exposure to $\mathrm{CO} 2$ laser radiation

\begin{tabular}{|c|l|l|}
\hline \multirow{2}{*}{ Coating material } & $\begin{array}{c}\text { The power density } \\
\text { of laser radiation } \mathrm{q}, \\
\mathrm{W} / \mathrm{cm}^{2}\end{array}$ & Average porosity $\mathrm{n}, \%$ \\
\hline \multirow{3}{*}{$\mathrm{Al}_{2} \mathrm{O}_{3}$} & 0 (initialstate) & 25 \\
\cline { 2 - 3 } & $1,6 \times 10^{6}$ & 18 \\
\cline { 2 - 3 } & $3,8 \times 10^{6}$ & 15 \\
\hline \multirow{3}{*}{$\mathrm{PN} 85-\mathrm{U}-15$} & 0 (initialstate) & 17 \\
\cline { 2 - 3 } & $1,5 \times 10^{6}$ & 8 \\
\cline { 2 - 3 } & $1,8 \times 10^{6}$ & 5 \\
\hline
\end{tabular}

\section{Conclusion}

1. It is established that exposure to laser radiation leads to a decrease in the average porosity of gas-thermal coatings based on various materials. For the coating on the basis of the alloy PN $85-\mathrm{U}-15$, the porosity decreases from $17 \%$ in the initial state to $5-8 \%$ after laser processing, for the ceramic coating $\mathrm{Al}_{2} \mathrm{O}_{3}-25 \%$ in the initial state to $15-18 \%$ after laser processing.

2. The greatest decrease in the porosity of all types of coatings occurs in the upper layers with a thickness of up to $50 \mu \mathrm{m}$. The presence of this layer with high density prevents the penetration of corrosive media to the metal substrate, reducing the likelihood of ulcerative corrosion, without changing the thermal protection properties of the coating.

\section{References}

1. V.V. Kudinov, Plazmennie pokritiya [Plasma coatings] (Nauka, Moscow, 1977)

2. A.A. Ryzhkin, A.V. Ilyasov, Vestnik DSTU, 2, 169 (2007)

3. A.F. Puzryakov, Teoreticheskie osnovi plasmennogo napileniya: Uchebnoe posobie po kursu "Tekhnologiya konstruktsii iz metallokompozitov" [Theoretical foundations of plasma spraying technology: A manual on the course "Technology of structures from metal composites"] (Bauman Moscow State Technical University, Moscow, 2003)

4. A.G. Grigoriants, I.N. Shiganov, A.I. Misyurov, Tekhnologicheskiye protsessy lazernoy obrabotki: Uchebnoe posobiye dlya vuzov [Technological processes of laser processing: Proc. Manual for universities] (Bauman Moscow State Technical University, Moscow, 2006)

5. Belova S.V., Poristyye pronitsayemyye materialy [Porous Permeable Materials], Moscow, Metalurgiya, 335 p., (1987)

6. S.A. Balashova, A.A. Mitrofanov, E.A. Chashchin, I.V. Shilov, Vestnik SSTU, 2, 72 (2009) 